\title{
Pyroclast formation processes during explosive kimberlite eruptions.
}

\author{
Ray Cas ${ }^{1}$, Lucy Porritt ${ }^{1}$, Pat Hayman ${ }^{1}$ and Adrian Pittari ${ }^{1}$ \\ ${ }^{1}$ School of Geosciences, Monash University, Clayton, Victoria, Australia, 3800.
}

\section{Introduction}

The pyroclasts of kimberlite deposits have anomalous features compared with those produced from explosive eruptions of other magma compositions. The pyroclasts of other magma types are either highly vesiculated irregular pumice (e.g. rhyolite) or scoria (e.g. basalt) fragments and cuspate glass shards where explosive activity is driven by volatiles, or are variably vesiculated, largely blocky glassy fragments for phreatomagmatic events.

By contrast, kimberlite pyroclasts are commonly either free whole crystals, mostly olivine, and spherical, or fluidal-shaped and non-vesiculated to weakly vesiculated juvenile pyroclasts. The spherical pyroclasts, called pelletal lapilli, commonly have a nucleus of an olivine crystal fragment, coated by a rim of chilled kimberlite melt that may contain crystals aligned concentrically around the core grain (Figure 1). In many volcanic systems, a poor degree of vesiculation is consistent with a phreatomagmatic origin, the low level of vesiculation being caused by early interaction of rising, vesiculating magma with external water, triggering explosive phreatomagmatic activity that arrests vesiculation before it can reach ist full potential.

Kimberlite magmas are commonly thought to have had high volatile contents, and we suggest the low vesicularity of kimberlite pyroclasts may be due to the low viscosity of kimberlite melt. The spherical form is inconsistent with a phreatomagmatic origin. We propose that crystals in the magma facilitated heterogeneous nucleation of vesicles around crystals (e.g. olivine) within the volcanic conduit. These vesicles grew very quickly in the low viscosity magma. As the magma fragmented into juvenile pyroclasts,

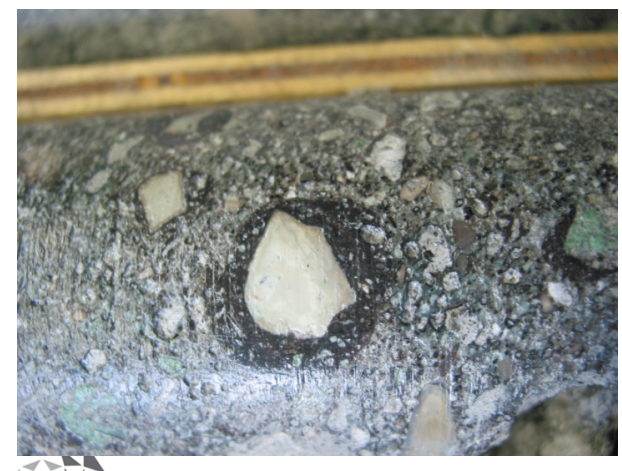

spinning in the eruption column or fountain, the zone of vesicles between the olivine crystal and the magma rind acted as a zone of weakness along which rotational shear and strain was partitioned. The outer magma rind sheared off in many cases and detached from the crystals, freeing many single whole olivine crystals, and producing a spray of kimberlite magma droplets from the rind.

In other pyroclasts, the low viscosity of the magma allowed the bubbles to rise buoyantly and "boil off" and out of the pyroclast prior to it quenching. Due to the low viscosity of the melt, the time necessary for bubble escape to occur is on the order of seconds, as calculated using Stokes Settling Law relationship. In addition, the spherical form of many pyroclasts is due to low magma viscosity and surface tension effects. Even fine ash particles are likely to be spherical, although recognition of original pyroclast shape in fragmental kimberlite deposits is limited by pervasive alteration of the matrix by serpentine and carbonate, which overprint all original matrix textures.

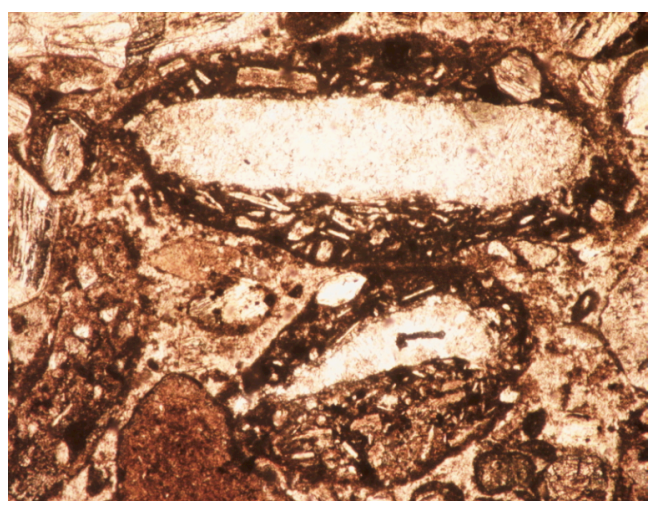

Figure 1 a. (left) Round pelletal lapillus with a fine rim of coherent kimberlite in olivine crystal rich, fragmental kimberlite in drill core, Muskox kimberlite, Northwest Territories, Canada. b. (above) Photomicrograph of non-vesicular juvenile pyroclasts (pelletal lapillus) in fragmental kimberlite, showing a rim of finely crystallised, chilled coherent kimberlite around a core of an elongate olivine crystal. Note some small elongate crystals are aligned concentrically around the core olivine grain in the top pelletal lapillus. Koffiefontein, South Africa. 